\title{
Coplanar capacitive coupled compact microstrip antenna for wireless communication
}

\author{
Swati Dhondiram Jadhav", Veeresh Gangappa Kasabegoudar \\ Post Graduate Department, Mahatma Basveshwar Education Society's, College of Engineering, Ambajogai, India, 431517
}

Email address:

swatijadhav5@gmail.com(S. D. Jadhav), veereshgk2002@rediffmail.com.com(V. G. Kasabegoudar)

To cite this article:

Swati Dhondiram Jadhav, Veeresh Gangappa Kasabegoudar. Coplanar Capacitive Coupled Compact Microstrip Antenna for Wireless Communication. International Journal of Wireless Communications and Mobile Computing. Vol. 1, No. 4, 2013, pp. 124-128. doi: 10.11648/j.wcmc.20130104.17

\begin{abstract}
In this paper, a coplanar capacitive coupled suspended microstrip antenna with reduced air gap (compact) for wireless applications is presented. Suspended microstrip antennas offer wide bandwidth due to the reduced effective dielectric constant and surface waves. However, air gap in the suspended configuration is the prime constraint in compact applications. Therefore, in this paper it is demonstrated that the air gap can be significantly reduced by utilizing the previously reported approaches and modifying them would result in significant reduction compared to the results reported earlier for the similar antenna geometries. The designs presented here exhibit the fractional impedance bandwidth of nearly $25 \%$ for all cases studied in the frequency range of $2-10 \mathrm{GHz}$.
\end{abstract}

Keywords: Microstrip Antennas, Suspended Configuration, Capacitive Coupling, Compact Antennas

\section{Introduction}

Microstrip patch antennas are rapidly developing in modern wireless communications, satellite and missile applications due to their attractive features such as low profile, light weight, and ease of fabrication. However, they have inherently narrow impedance bandwidth. There are various methods to overcome this serious drawback to achieve ultra-wideband (UWB) performance. Since the frequency range of UWB wireless standard has been allocated from $3.1 \mathrm{GHz}$ to $10.6 \mathrm{GHz}$ [1], nowadays obtaining a compact wideband antenna is exclusively noticeable in commercial and military systems. The antennas proposed here operate in L-, S-, C-, and X-bands, which are suitable for UWB applications such as wireless personal area network (WPAN), microwave imaging for detecting tumors and cancers, medical monitoring, and home networking applications. There are several techniques for impedance bandwidth enhancements which are reported by many researchers such as by using impedance matching network [2], stacked patches [3], using edge coupled parasitic patches [2-4], by changing the shape of geometry [5], by cutting slots into basic stapes [6]. Broad banding techniques can also be achieved by modifying the probe shape [7-9]. At the time of the fabrication and assembly some bandwidth enhancement techniques pose problems due to the use of multiple metal or dielectric layers in the geometries.

There are several microstrip patch antennas available in literature which utilize single layer. For example, single layer coplanar capacitive coupled probe fed suspended microstrip antennas [9-15] are simple to realize and offer high impedance bandwidth of nearly $50 \%$. It is well known that bandwidth enhancement can be achieved by increasing the overall height of the composite air-dielectric medium [10-14]. However, the use of air gap increases the height/volume of the antenna which is undesired in several compact applications [15-18].

In this paper we have taken the compact geometry reported in [15] for the further investigation and tried to reduce the air gap further by more than $50 \%$ which is a significant reduction and useful in several compact applications. Section 2 presents the basic geometry of the antenna. The procedure of air gap reduction by selecting any center frequency is presented in Section 3. Parametric studies for optimization of air gap are presented in Section 4 followed by conclusions in Section 5 .

\section{Basic Geometry}

Basic geometry of the antenna is shown in Figure 1 and its optimized dimensions are listed in Table 1 [15]. It consists of radiating patch and a rectangular feed strip which are etched 
on the same plane. The substrate is placed above the ground plane at a height equal to air-gap. This height of air gap plays a vital role for broad banding. The substrate used for the antenna design is a Rogers' make RO3003 with dielectric constant $=3.0$, loss tangent $(\tan (\delta))=0.0013$ and thickness $(h)=1.56 \mathrm{~mm}$.

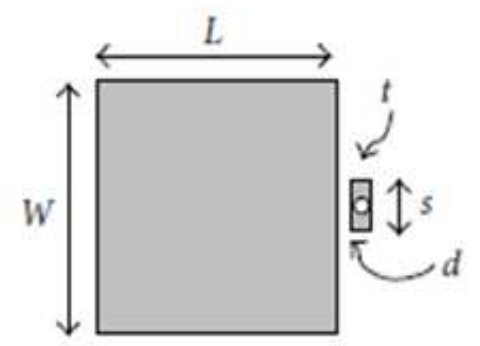

(a) Top view

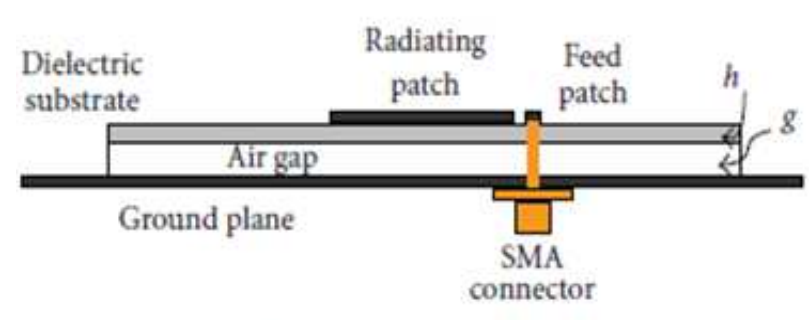

(b) Cross-sectional view

Figure 1. Geometry of a rectangular patch antenna with a small capacitive feed arrangement [10].

Table 1. Dimensions for the antenna designed for $10 \mathrm{GHz}$.

\begin{tabular}{lc}
\hline Parameter & Value \\
\hline Length of the radiator patch $(L)$ & $7.8 \mathrm{~mm}$ \\
Width of the radiator patch $(W)$ & $10.6 \mathrm{~mm}$ \\
Length of the feed strip $(t)$ & $2 \mathrm{~mm}$ \\
Width of the feed strip $(s)$ & $5.2 \mathrm{~mm}$ \\
Separation of feed strip from the patch $(d)$ & $0.5 \mathrm{~mm}$ \\
Air gap between substrates $(g)$ & $0.6 \mathrm{~mm}$ \\
Relative dielectric constant $\left(\varepsilon_{\mathrm{r}}\right)$ & 3.0 \\
Thickness of substrate $(h)$ & $1.56 \mathrm{~mm}$ \\
\hline
\end{tabular}

For the optimization of all parameters IE3D is used which is method of moments (MoM) based electromagnetic (EM) software. The basic design of patch is started by selecting the center frequency as suggested in [10]. It has been shown that the impedance bandwidth of the antenna can be maximized by using the air gap value given in [10].

$$
g \cong 0.16 \lambda_{0}-h \sqrt{\varepsilon_{r}}
$$

Where, $\mathrm{g}$ is the height of substrate above the ground, $\mathrm{h}$ is the thickness of the substrates, and $\varepsilon_{r}$ is dielectric constant of the substrate. However, equation (1) is used to calculate the initial value. Final optimized values would be within $\pm 5 \%$ of this value [10]. The parameters considered for optimization are the height of substrate above the ground $(g)$, the thickness of the substrates $(h)$ separation between feed strip and patch $(d)$ and feed strip dimensions (length $(t)$, and width $(s)$ ). The complete optimization procedure of these key design parameters is presented in [10]. In this work optimization procedure is adopted for further reduction in air gap and is presented in detail in Section 3.

\section{Parametric Studies and Discussion}

As stated in Section 2, the geometry shown in Figure 1 was simulated using IE3D software. All key design parameters (length $(t)$, width $(s)$ and distance between feed strip and patch $(d)$ ) have been investigated to analyze the effect on antenna performance and are discussed in the following subsections

The air gap is reduced by keeping the impedance bandwidth high for compact applications as mentioned earlier. In order to reduce size of the proposed antenna geometry, an air gap was reduced in steps of $0.1 \mathrm{~mm}$ and feed strip parameters (length $(t)$, width $(s)$ and distance between feed strip and patch $(d)$ ) were re-optimized in each case. Variations in the parameters are stopped wherever the optimum bandwidth is obtained. The relation between reduction in air gap value and change in feed strip dimension are suggested in [15].

$$
\begin{aligned}
& g_{\text {modiried }}=g_{\text {opt }}+\Delta g \\
& s_{\text {midified }}=s_{\text {opt }}+\Delta s
\end{aligned}
$$

In (2) and (3), $g_{\text {opt }}$ and $s_{\text {opt }}$ are the optimized air gap and feed strip width, respectively, as defined in [10]. And,

$$
\begin{aligned}
& \Delta s \approx 1.5 \Delta g\left(\Delta g \leq g_{o p t} / 2\right) \\
& \Delta s \approx 1.75 \Delta g\left(\Delta g>g_{o p t} / 2\right)
\end{aligned}
$$

It should be noted that $s_{\text {modified }}<\mathrm{W}$ (width of the radiator patch) [15]. As suggested in [10]-[13] the parameter ' $s$ ' controls the resistive part and ' $d$ ' changes the reactive component of the input impedance. We have considered the optimized values as mentioned in [15] as a reference case and varied length of the feed strip ' $t$ ' and stopped where the maximum impedance bandwidth is obtained. This procedure is repeated for remaining parameters, and finally considered all optimized values to obtain the high impedance bandwidth.

In this work besides procedure suggested in [15] for the reduction of air gap, other parameters have also been varied to get the further reduction in air gap value. As an example, $10 \mathrm{GHz}$ design reported in [15] is reconsidered for further optimization of air gap value. As reported in [15], the best possible minimum value of air gap is $0.6 \mathrm{~mm}$. In this we have demonstrated that this value can be further reduced to $0.1 \mathrm{~mm}$ keeping antenna's input impedance reasonably high (38\%) and is suitable for FCC defined UWB applications. The optimization procedure is started from the minimum 
value of air gap reported in [15]. The optimization procedure for $g=0.5 \mathrm{~mm}$ is presented in the following paragraphs and similar procedure has been adopted for other values of air gap values.

\subsection{Effect of Distance between Feed Strip and Patch (d)}

In order to reduce the air gap, dimensions of the feed strip and distance between feed strip and patch have been optimized. Width of the feed strip $(s)$ is calculated using equation (3). The air gap is reduced in steps of $0.1 \mathrm{~mm}$, and for each value of air gap $(g)$ other parameters $(s, t$, and $d)$ have re-optimized. As an example, for air gap value of 0.5 $\mathrm{mm}$, optimization procedure is presented. The distance between feed strip and patch $(d)$ dimensions are varied from $0.1 \mathrm{~mm}$ to $0.55 \mathrm{~mm}$ by keeping $t=2 \mathrm{~mm}$ and $s=5.35 \mathrm{~mm}$ constant. Optimized value obtained for this case is $d=0.5$ $\mathrm{mm}$ (pl. ref. Figure 2).

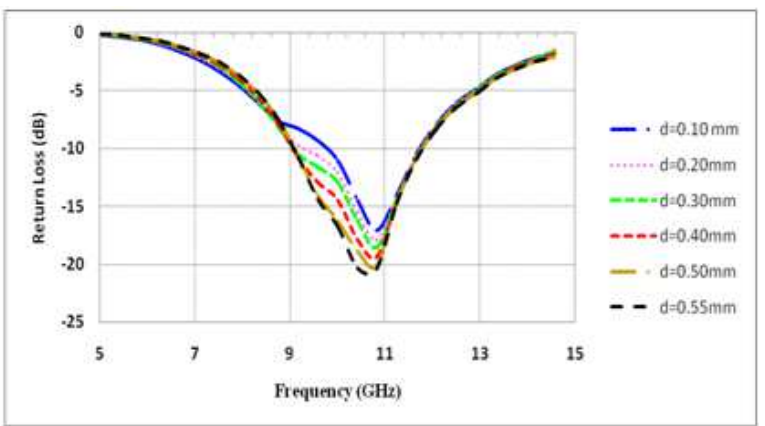

Figure 2. Return loss characteristics with the variation in separation between radiator and feed strip (d).

\subsection{Effect of Feed Strip Length (t)}

The length of the feed strip $(t)$ is varied from $1.9 \mathrm{~mm}$ to $2.3 \mathrm{~mm}$ in steps of $0.1 \mathrm{~mm}$ by keeping the distance between feed strip and patch $d=0.5 \mathrm{~mm}$ (as obtained in Section 3.1) and width of the feed strip $s=5.35 \mathrm{~mm}$. The return loss characteristic for this case is shown in Figure 3. From the Figure 3 it may be noted the maximum bandwidth is achieved for feed strip length $t=2.2 \mathrm{~mm}$.

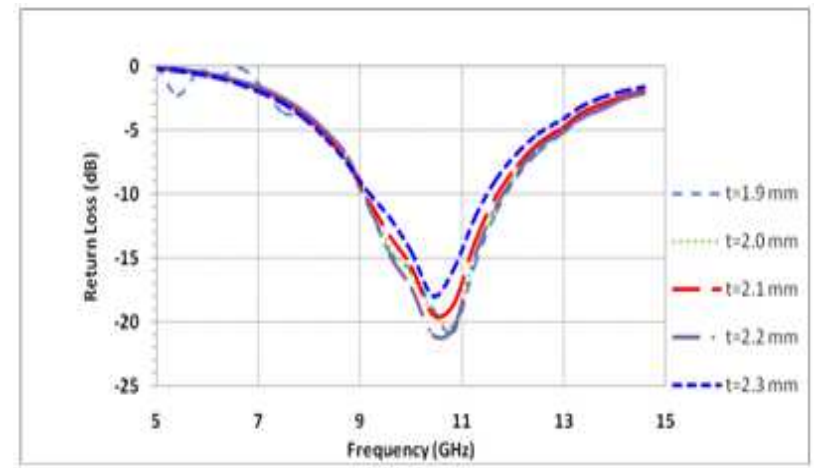

Figure 3. Return loss characteristics with the variation in feed strip length (t).

\subsection{Effect of Feed Strip Width (s)}

Finally, the width of feed strip $(s)$ is varied from $4.35 \mathrm{~mm}$ to $5.85 \mathrm{~mm}$ in a steps of $0.5 \mathrm{~mm}$ by keeping the optimum values obtained in previous sub sections $t=2.2 \mathrm{~mm}$ and $d=0.5 \mathrm{~mm}$. The return loss characteristics for this case are presented in Figure 4.From Figure 4 it may be noted that the optimized value for this case is $s=5.35 \mathrm{~mm}$.

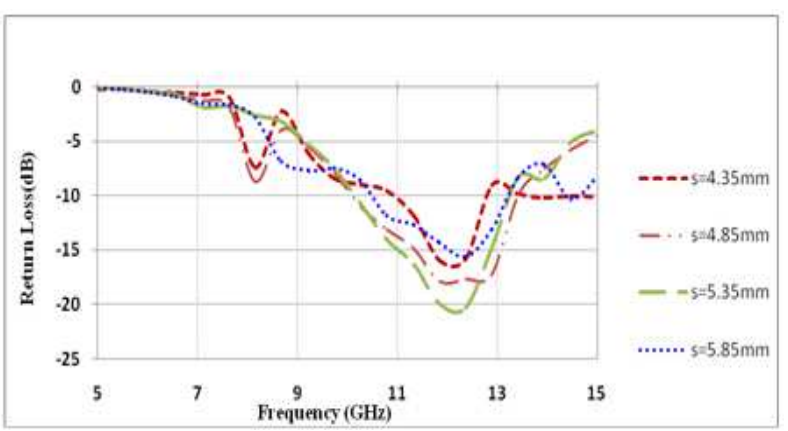

Figure 4. Return loss characteristics with the variation in feed strip width (s).

It may be noted that similar procedure is followed for air gap values of $0.3 \mathrm{~mm}, 0.2 \mathrm{~mm}$, and for $0.1 \mathrm{~mm}$. The optimized parameters for different air gap values of $10 \mathrm{GHz}$ are shown in Table 2.

Table 2. Re-optimized values of feed strip length, width and $\% B W$ for reduced air gap values of $10 \mathrm{GHz}$.

\begin{tabular}{cccccc}
\hline Air gap (mm) & 0.5 & 0.4 & 0.3 & 0.2 & 0.1 \\
\hline $\boldsymbol{t}, \boldsymbol{s}(\mathbf{m m})$ & $2.2,4.85$ & $1.2,5.5$ & $1.2,5.65$ & $1.2,4.3$ & $2,4.45$ \\
$\mathbf{B W} \%$ & 40.0 & 39.8 & 41.0 & 32.9 & 38.8 \\
\hline
\end{tabular}

The optimized air gap value obtained from the above studies is $0.1 \mathrm{~mm}$ with impedance bandwidth of about $38 \%$. Obtained return loss characteristics for $10 \mathrm{GHz}$ with different air gap values are shown in Figure 5. It may be noted that center frequency is shifted as the air gap reduces shown in Figure 5. However, the shift in the center frequency may be re-tuned to some extent by loading such as placing a slot on it [16].

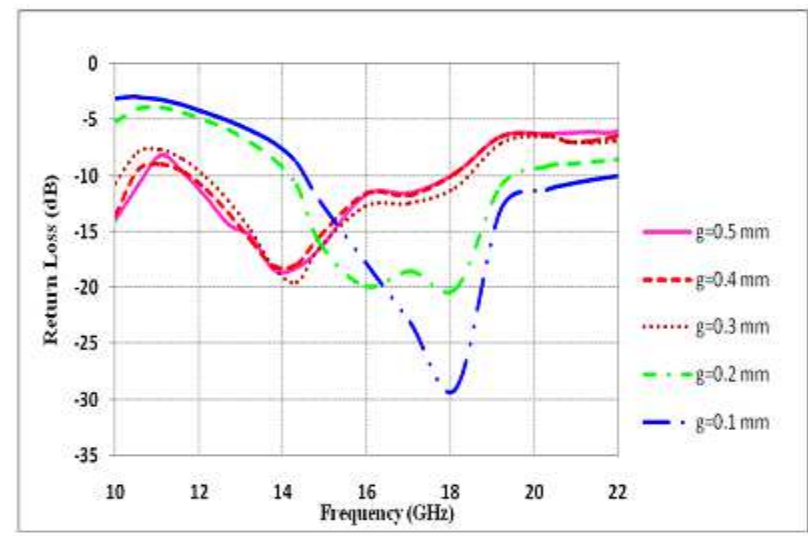

Figure 5. Simulated return loss characteristics of geometry of $10 \mathrm{GHz}$ for different air gap values.

It may be noted that the reduction in the air gap at higher operating frequencies results in the shift in center frequency. 
The similar procedure has been followed for the different center frequencies $2 \mathrm{GHz}, 4.5 \mathrm{GHz}, 5.9 \mathrm{GHz}$, and $8 \mathrm{GHz}$. For the center frequencies of 8 and $10 \mathrm{GHz}, 90.00 \%$ and
$83.33 \%$ air gap reductions have been achieved with the percentage bandwidths of $28.8 \%$ and $38.8 \%$ respectively. The obtained results for these cases are presented in Table 3 .

Table 3. Amount of air gap reduction and \% bandwidth obtained for different bands of frequencie $s$

\begin{tabular}{|c|c|c|c|c|c|c|c|c|}
\hline $\begin{array}{c}\text { Center freq. }\left(f_{c}\right) \\
(\mathbf{G H z})\end{array}$ & $\begin{array}{c}\text { Radiator patch } \\
\text { dimensions } \\
\text { L,W (mm) }\end{array}$ & $\begin{array}{c}t, s(\mathrm{~mm}) \\
{[15]}\end{array}$ & $\begin{array}{c}t, s(\mathrm{~mm}) \\
\text { (this work) }\end{array}$ & $\begin{array}{l}\text { Opt. air } \\
\text { gap } g_{o p t} \\
(\mathrm{~mm})[15]\end{array}$ & $\begin{array}{l}\text { Optimum air } \\
\text { gap (mm) } \\
\text { (this work) }\end{array}$ & $\begin{array}{c}\text { BW (\%) } \\
{[15]}\end{array}$ & $\begin{array}{c}\text { BW (\%) } \\
\text { (this work) }\end{array}$ & $\begin{array}{c}\text { Air gap } \\
\text { reduction (\%) }\end{array}$ \\
\hline 2.0 & $42.8,53.0$ & $3.0,13$ & $2.5,14.5$ & 8.50 & 7.50 & 34.5 & 29.02 & 11.76 \\
\hline 4.5 & $21.0,26.5$ & $2.0,10$ & $2,10.75$ & 3.50 & 3.00 & 32.9 & 34.16 & 14.28 \\
\hline 5.9 & $15.5,16.4$ & $1.2,10$ & $1.4,9.8$ & 2.25 & 1.75 & 34.5 & 34.58 & 22.22 \\
\hline 8.0 & $10.0,13.2$ & $2.0,5.2$ & $2,6.85$ & 1.00 & 0.10 & 48.5 & 28.83 & 90.00 \\
\hline 10.0 & $7.8,10.6$ & $2.0,5.2$ & $2,4.45$ & 0.60 & 0.10 & 48.3 & 38.88 & 83.33 \\
\hline
\end{tabular}

\section{Conclusions}

A procedure for reduction of air gap of coplanar capacitively coupled suspended microstrip antenna has been presented. An effort has been made (in all cases presented) to reduce the air gap significantly keeping all other parameters (of antenna geometry) optimum especially impedance bandwidth of nearly $25 \%$ which is suitable for most of the FCC defined UWB applications. It has been shown that more than $80 \%$ air gap reduction can be achieved at $8 \mathrm{GHz}$, and $10 \mathrm{GHz}$, respectively, compared to previously published works for similar antenna geometries. The antenna presented here proves to be the best candidate for the FCC defined compact wireless applications (UWB).

\section{References}

[1] J. A. Wei, "Applications on Ultra Wideband," M. S. Report, University of Texas at Arlington, 2006.

[2] P. Bhartia, K. Rao, and R. Tomar, Millimeterwave Micro strip and Printed Circuit Antennas, Artech House, Canton, MA, 1991.

[3] D. M. Pozar and D. H. Schaubert, Microstrip Antennas, the Analysis and Design of Microstrip Antennas and Arrays, IEEE Press, New York, 1995.

[4] G. Kumar and K. Gupta, "Directly coupled multiple resonator wide-band microstrip antenna," IEEE Transactions and Propagations, vol. 33. no. 6, 1985.

[5] B. L. Ooi, and I. Ang, "Broadband semicircle fed flower-shaped microstrip patch antenna," Electron. Lett., vol. 41, no. 17, 2005.

[6] K. M. Luk, K. F. Lee, and W. L. Tam, "Circular U-slot patch with dielectric substrate," Electronics Lett., vol.33, no.12, pp. 1001-1002, 1997.

[7] C. L. Mak, K. F. Lee and K. M. Luk, "A novel broadband patch antenna with T-shaped probe," Proc. Inst. Elect. Engg
Microw., Antennas Propagat., vol. 147, pp. 73-76, 2000.

[8] H. W. Lai and K. M. Luk, "Wideband stacked patch fed by meandering probe," Electron. Lett., vol. 41, no. 6, 2005.

[9] Mathew-Ridgers, G., J.W. Odondaal, and J. Joubert, "Single layer capacitive feed for wideband probe-fed microstrip antenna elements," IEEE Trans. Antennas Propagat., vol. 51, pp. 1405-1407, 2003.

[10] V. G. Kasabegoudar, D. S. Upadhyay, and K. J. Vinoy, "Design studies of ultra wideband microstrip antennas with a small capacity feed," Int. J. Antennas Propagat., pp. 1-8, 2007.

[11] V. G. Kasabegoudar and K. J. Vinoy, "A wideband microstrip antenna with symmetric radiation patterns," Microw. Opt. Technol. Lett., vol. 50, no. 8, pp. 1991-1995, 2008.

[12] V. G. Kasabegoudar and K. J. Vinoy, "Coplanar capacitively coupled probe fed microstrip antennas for wideband applications," IEEE Trans. Antennas Propagat.," vol. 58, no. 10, pp. 3131-3138, 2010.

[13] V. G. Kasabegoudar and K. J. Vinoy, "A broadband suspended microstrip antenna for circular polarization," Progress in Electromagnetics Research, vol. 90, pp. 353-368, 2009.

[14] V. G. Kasabegoudar, "Dual frequency ring antenna with capacitive feed," Progress in Electromagmetics Research C, vol. 23, pp. 27-39, 2011.

[15] V. G. Kasabegoudar, "Low profile suspended microstrip antennas for wideband applications," Journal of Electromagnetic Waves and Applications, vol. 25, no. 13, pp. 1795- 1806, 2011.

[16] V. G. Kasabegoudar and K. J. Vinoy, "A coplanar capacitively coupled probe fed microstrip antenna for wireless applications," Int. Symposium on Antennas and Propagation, pp. 297-300, 2009.

[17] V. G. Kasabegoudar and K. J. Vinoy, "Input impedance modelling of capacitively coupled wideband microstrip antenna," Int. Symposium on Antennas and Propagat., pp. 268-271, 2008. 
[18] V. G. Kasabegoudar and A. Kumar, "Dual band capacitive coupled microstrip antennas with and without air gap for wireless applications," Progress in Electromagnetics Research C, vol. 36, pp. 105-117, 2013.
[19] "New public safety applications and broadband internet access among uses envisioned by FCC authorization of ultra wideband technology." First report and order (FCC 02-48), action by the Commission, February, 2002. 